\title{
Update on flow diverters for the endovascular management of cerebral aneurysms
}

\author{
Gary Rajah, MD, Sandra Narayanan, MD, and Leonardo Rangel-Castilla, MD \\ Department of Neurosurgery, Wayne State University School of Medicine, Detroit, Michigan
}

Flow diversion has become a well-accepted option for the treatment of cerebral aneurysms. Given the significant treatment effect of flow diverters, numerous options have emerged since the initial Pipeline embolization device studies. In this review, the authors describe the available flow diverters, both endoluminal and intrasaccular, addressing nuances of device design and function and presenting data on complications and outcomes, where available. They also discuss possible future directions of flow diversion.

https://thejns.org/doi/abs/10.3171/2017.3.FOCUS16427

KEY WORDS intracranial aneurysm; flow diversion; Pipeline embolization device; SILK flow diverter; Surpass flow diverter; FRED; WEB; Medina; LUNA AES; p64

$\mathrm{E}$ NDOVASCULAR coils for intracranial aneurysms were first used in the $1980 \mathrm{~s} .{ }^{15}$ In the early $1990 \mathrm{~s}$, researchers had already used a stent-like endoprosthesis in a mongrel dog model for treatment of experimental carotid artery aneurysms, demonstrating exclusion of the aneurysm. ${ }^{84}$ One of the first reported stent-assisted coiling procedures took place in 1997 for a ruptured fusiform vertebrobasilar artery aneurysm, and the success of this procedure was announced in a case report. ${ }^{37}$ The first clinical use of a flow diverter (Pipeline embolization device [PED]) in North America was reported in 2008 and involved treatment of patients with fusiform vertebral artery (VA) aneurysms. ${ }^{29}$ While stents and flow diverters have different indications for vessel reconstruction/embolization, their beginnings are not unrelated. By 1999, authors of in vitro and in vivo studies utilizing stents had noted hemodynamic uncoupling of aneurysms with stents alone; unfortunately, the high porosity of the stents that were available at that time precluded useful flow diversion. ${ }^{52,88}$

Between the 1990s and 2008, the so-called intracranial stent underwent significant gain-of-function mutations to arrive at intracranial aneurysm occlusion via flow diversion. While high radial opening force may be important for stents acting as scaffolding, this is not the case with flow diverters, which are designed to have low radial opening forces in an attempt to facilitate navigability. In addition, flow diverters need to have greater metal coverage and decreased porosity, while maintaining pore density. One way this was achieved was via a braided metallic design. A porosity of $70 \%$ is reported to be the ideal porosity for aneurysm occlusion. ${ }^{77}$ Filament size is important as it can be related to intraaneurysmal circulation and side-branch artery patency. ${ }^{53}$ PEDs implanted in rabbits have been shown not to occlude adjacent branches, despite successful aneurysm occlusion and device endothelialization. ${ }^{40}$ Thus flow diversion treats aneurysms first through mechanical redirection of blood flow, which allows for intraaneurysmal stagnation of blood, clot formation, remodeling, and, ultimately, endothelial growth. Long-term normalization through remodeling and resorption has been reported. ${ }^{28}$

The flow diverter has become a separate entity from the stent, with a different purpose and set of indications. Originally the PED was indicated for wide-necked or fusiform aneurysms from the petrous segment to the clinoid segment of the internal carotid artery (ICA); ${ }^{32}$ nowadays, however, flow diversion is being more broadly applied to small aneurysms, ${ }^{34}$ anterior cerebral artery aneurysms, ${ }^{24}$ $\mathrm{M}_{3}-\mathrm{M}_{4}$ aneurysms, ${ }^{27}$ recurrent aneurysms, ${ }^{16}$ dissect-

ABBREVIATIONS AES = aneurysm embolization system; AP = anteroposterior; ASPIRe = Aneurysm Study of Pipeline in an Observational Registry; FRED = flow redirection endoluminal device; Gpllb/llla = glycoprotein Ilb/llla; ICA = internal carotid artery; ID = inner diameter; IntrePED = International Retrospective Study of Pipeline Embolization Device; LVIS = low-profile visualized intraluminal; MCA = middle cerebral artery; PED = Pipeline embolization device; PITA = The Pipeline Embolization Device for the Intracranial Treatment of Aneurysms; PUFS = Pipeline for Uncoilable or Failed Aneurysms; RADAR = Retrospective Analysis of Delayed Aneurysm Ruptures after Flow Diversion; VA = vertebral artery; WEB = Woven EndoBridge; WEBCAST = WEB Clinical Assessment of Intrasaccular Aneurysm Therapy.

SUBMITTED October 17, 2016. ACCEPTED March 9, 2017.

INCLUDE WHEN CITING DOI: 10.3171/2017.3.FOCUS16427. 
ing aneurysms, ${ }^{31}$ ruptured aneurysms, ${ }^{50,60}$ and posterior circulation aneurysm. ${ }^{42}$ Multiple flow diverters are currently available: the Pipeline embolization device (PED, Medtronic), Surpass (Stryker), FRED (flow redirection endoluminal device, MicroVention), SILK (Balt Extrusion), and p64 (Phenox). A new generation of intraluminal support devices incorporate braided designs with $18 \%-22 \%$ metal coverage and possible flow-modifying properties. These include: LVIS (low-profile visualized intraluminal support device, MicroVention), LVIS Jr. (MicroVention), and LVIS Blue (MicroVention). Incidentally, 2 overlapping LVIS devices have been reported to create a better flowdiverting effect than a single PED.$^{89}$ Other recent developments in flow diversion/disruption include intrasaccular devices such as WEB (Woven EndoBridge, Sequent Medical), Medina embolic device (Medtronic), and LUNA AES (aneurysm embolization system, Nfocus Neuromedical).

\section{Treatment Effect and Durability}

A large meta-analysis of studies including a total of 1654 intracranial aneurysms treated with flow diverters found an overall $76 \%$ occlusion rate. ${ }^{13}$ Authors of other meta-analyses have reported similar overall occlusion rates. ${ }^{92,94}$ A meta-analysis reviewing blister aneurysms found that, of the reconstructive treatments, flow diverters were associated with higher rates of occlusion $(90 \%$ vs $67 \%$ ) and lower rates of retreatment than other reconstructive methods. ${ }^{75} \mathrm{~A}$ recent meta-analysis of flow-diverter treatment for 225 posterior circulation aneurysms noted an $84 \%$ occlusion rate at 6 months with overall good outcomes in $79 \%$ of patients. However, patients with ruptured aneurysms and basilar artery aneurysms were significantly less likely to have a good outcome. ${ }^{90}$ The Buenos Aires experience of 1000 patients treated with flow diverters (633 of whom were treated with PED) noted 1-year and 8-year occlusion rates of $80 \%$ and $100 \%$, respectively, without recurrences. ${ }^{57}$

\section{Complications and Technical Difficulties}

A meta-analysis of flow-diverter treatment of intracranial aneurysms found that the procedure-related morbidity and mortality were $5 \%$ and $4 \% .^{13}$ The rates of perforator infarction (more common in the posterior circulation) and intraparenchymal hemorrhage were $3 \%$ each. In an international retrospective study of risk factors for complications following PED treatment, 15\% of intracranial hemorrhages were contralateral to the side of PED placement. ${ }^{12}$ Speculation exists about the cause of intraparenchymal hemorrhage, especially contralateral to the device. Theories include embolized sheath material with hemorrhagic transformation of ischemic infarct in the setting of dualantiplatelet therapy, flow changes, and platelet dysfunction from shear over the device. Another meta-analysis examining only posterior circulation aneurysms noted a $15 \%$ mortality rate among patients treated with flow diversion, with the risk of mortality being greater in patients with giant aneurysms; ischemic and perforator infarcts were observed in $11 \%$ and $7 \%$ of patients, respectively. ${ }^{90}$ In a recent study incorporating diffusion-weighted imaging performed 24 hours after PED placement, $62 \%$ of patients were found to have clinically silent ischemic infarcts. ${ }^{6}$ Ipsilateral FLAIR changes of uncertain etiology and consequence have been identified in $34 \%$ of patients. ${ }^{78}$ Higher rates of complications have been reported for the treatment of aneurysms in the posterior circulation and distal cerebral vasculature. ${ }^{58}$ Rangel-Castilla et al ${ }^{74}$ found a long-term rate of side-branch occlusion of $15.8 \%$ after flow-diverter treatment; however, these occlusions appeared to be clinically silent. Terminal branch occlusions in vessels such as the anterior choroidal artery were not observed. Colby et al. ${ }^{22}$ noted that resheathing occurred in 9\% of Pipeline Flex cases, and $98 \%$ of devices were successfully placed in their series. Delayed aneurysm rupture after PED use has been reported and may result in carotid-cavernous fistula. Roy et al. reported a $11.4 \%$ rate of carotid-cavernous fistula occurrence after PED treatment, with all of the fistulas occurring within 2 weeks of PED placement. ${ }^{76}$ In a study of 17 patients treated with flow diversion, Berge et al. ${ }^{5}$ noted that $41 \%$ experienced an exacerbation of symptoms related to perianeurysmal edema and inflammation after treatment. MRI findings have supported this inflammation theory. ${ }^{5}$ The RADAR study (Retrospective Analysis of Delayed Aneurysm Ruptures after Flow Diversion) ${ }^{49}$ reported a $2.1 \%$ risk of delayed ruptured for aneurysms larger than $10 \mathrm{~mm}$ in diameter (mean $24 \mathrm{~mm}$ ), with a median time from treatment to rupture of 9 days. Potential mechanisms of delayed rupture include persistent inflow jet after treatment, thrombosis/expansion of the aneurysm due to stagnation of flow, and clot-induced autolysis of the aneurysmal wall. ${ }^{14,48} \mathrm{John}$ et al..$^{38}$ reported a $9.8 \%$ rate of in-stent stenosis at a median of 6 months after PED treatment. However, no significant clinical effects occurred, and there was significant improvement at further follow-up noted related to the stenosis; no stenosis required retreatment. PED migration can also occur, and was reported in $0.5 \%$ of cases in one study. ${ }^{17}$ Persistent aneurysm growth following PED placement has been reported for a fusiform VA aneurysm..$^{43}$ The IntrePED study ${ }^{41}$ retrospectively assessed neurological complication rates with PED. A total of 906 aneurysms were included, and the overall rate of neurological morbidity and mortality was $8.4 \%$; the rate was highest in cases of posterior circulation aneurysms (16.4\%). The lowest neurological morbidity and mortality rate in that study was for small $(<10 \mathrm{~mm})$ ICA aneurysms $(4.8 \%)$. The spontaneous rupture rate was $0.6 \%$, and the rates of ischemic and hemorrhagic strokes were $4.7 \%$ and $2.4 \%$, respectively. The rate of ischemic stroke in the posterior circulation was $7.3 \%$. In a more recent study utilizing the same registry, Brinjikji et al..$^{11}$ found a $4.5 \%$ rate of ischemic stroke. Variables contributing to acute ischemic stroke included male sex, hypertension, fusiform aneurysm, middle cerebral artery (MCA) aneurysm, giant aneurysm, and multiple PEDs. However, on multivariable analysis the only variable associated with postoperative stroke was fusiform aneurysm. ${ }^{11}$ The recently published ASPIRe study ${ }^{39}$ prospectively analyzed occlusion rates and neurological events following PED placement. Two hundred seven aneurysms were treated (mean aneurysm size of $14.5 \mathrm{~mm}$, median imaging follow-up of 7.8 months). This study reported neurological morbidity and mortality rates of $6.8 \%$ and $1.6 \%$, respectively. The rate of complete occlusion on last imaging follow-up was $74.8 \%$. The au- 
TABLE 1. Summary of characteristics of endoluminal flow diverters

\begin{tabular}{|c|c|c|c|c|c|c|c|}
\hline $\begin{array}{l}\text { Flow } \\
\text { Diverter }\end{array}$ & $\begin{array}{l}\text { Available } \\
\text { Diameter }\end{array}$ & $\begin{array}{l}\text { Available } \\
\text { Length }\end{array}$ & Material & Design & Deployment & Resheathable? & $\begin{array}{c}\text { Manufacturer-Reported } \\
\text { Strengths }\end{array}$ \\
\hline Pipeline & $2.5-5 \mathrm{~mm}$ & $10-35 \mathrm{~mm}$ & $\begin{array}{l}\text { Cobalt chrome } \\
\text { w/ platinum } \\
\text { tungsten }\end{array}$ & 48 braided strands & $\begin{array}{l}\text { Pusher wire w/ } \\
\text { unsheath- } \\
\text { ing }\end{array}$ & $\begin{array}{l}\text { Yes, full length } \\
\quad \text { (Flex) }\end{array}$ & $\begin{array}{l}\text { Flex has 4-point Flex technol- } \\
\text { ogy \& is fully resheathable } \\
\text { compared to original }\end{array}$ \\
\hline Surpass & $2-5 \mathrm{~mm}$ & $12-50 \mathrm{~mm}$ & $\begin{array}{l}\text { Cobalt chrome } \\
\text { w/ platinum } \\
\text { tungsten }\end{array}$ & $\begin{array}{l}\text { 2-mm, 3- to 4-mm, \& } \\
\text { 5-mm }(48,72,96) \\
\text { braided strands, } \\
\text { respectively }\end{array}$ & $\begin{array}{l}\text { 3.7-Fr distal } \\
\text { catheter } \\
\text { w/ pusher } \\
\text { catheter }\end{array}$ & $\begin{array}{l}\text { Yes, up to } 11 \mathrm{~mm} \\
\text { btwn catheter } \\
\text { tip \& pusher } \\
\text { must remain }\end{array}$ & $\begin{array}{l}\text { Surpass Streamline has } 67 \% \text {, } \\
61 \%, \& 34 \% \text { less tracking } \\
\text { force than Legacy, Pipeline, } \\
\text { or FRED, respectively }\end{array}$ \\
\hline SILK & $2-5 \mathrm{~mm}$ & $15-40 \mathrm{~mm}$ & $\begin{array}{l}\text { Nitinol w/ } \\
\text { platinum }\end{array}$ & 48 braided strands & $\begin{array}{l}\text { Push-pull } \\
\text { deployment }\end{array}$ & $\begin{array}{l}\text { Yes, SILK (+) up } \\
\quad \text { to } 90 \%\end{array}$ & $\begin{array}{l}\text { SILK }(+) \text { available in tapered } \\
\text { sizes, has enhanced visibility } \\
\text { compared to SILK }\end{array}$ \\
\hline FRED & $3.5-5.5 \mathrm{~mm}$ & $7-56 \mathrm{~mm}$ & $\begin{array}{l}\text { Nitinol w/ } \\
\text { interwoven } \\
\text { tantalum }\end{array}$ & $\begin{array}{l}\text { Dual-layer braided design; } \\
48 \text { braided strands in- } \\
\text { ner, } 16 \text { braided stands } \\
\text { outer stent }\end{array}$ & $\begin{array}{l}\text { Push-pull } \\
\text { deployment }\end{array}$ & Yes, up to $80 \%$ & $\begin{array}{l}\text { Unique integrated dual-layer } \\
\text { design that can be simulta- } \\
\text { neously deployed or partially } \\
\text { retrieved by single operator }\end{array}$ \\
\hline p64 & $2.5-5 \mathrm{~mm}$ & $12-36 \mathrm{~mm}$ & Nitinol & 64 braided strands & $\begin{array}{l}\text { Mechanical } \\
\text { detachment }\end{array}$ & Yes & $\begin{array}{l}\text { Complete deployment w/ full } \\
\text { recoverability }\end{array}$ \\
\hline
\end{tabular}

thors concluded that PED treatment of aneurysms in a heterogeneous population was safe, with low neurological morbidity rates and good occlusion rates.

Lastly, flow diversion does not work for all aneurysms. Persistent posttreatment filling of posterior communicating artery aneurysms associated with a fetal posterior cerebral artery have been reported in patients treated with PED. ${ }^{93}$ Another study of PED use for 16 aneurysms with an incorporated vessel supplying a territory without collateral circulation (end territory) revealed persistent patency of all aneurysms at 24 months after treatment. The aneurysm locations were as follows: posterior communicating artery $(n=7)$, ophthalmic $(n=5)$, superior cerebellar artery $(n=1)$, anterior inferior cerebellar artery $(n=1)$, and MCA aneurysms $(\mathrm{n}=2){ }^{42}$ Paraophthalmic aneurysms with the ophthalmic artery origin from the dome appear to have lower rates of occlusion and ophthalmic artery patency, as well as more transient visual symptoms. ${ }^{35}$ In comparison with PED treatment of previously untreated aneurysms, PED treatment of previously stented, recurrent aneurysms is associated with higher morbidity and lower occlusion rates. ${ }^{25}$

\section{Endoluminal Flow-Diverter Devices}

Please see Table 1 for a tabular comparison of devices.

\section{Pipeline}

The Pipeline embolization device (PED) is a self-expanding cylindrical device. It is composed of 48 braided strands of cobalt-chromium and platinum-tungsten wire in a 3:1 ratio. The device ranges from 2.5 to $5 \mathrm{~mm}$ in diameter and from 10 to $35 \mathrm{~mm}$ in length and opens $0.25 \mathrm{~mm}$ wider than the nominal diameter. The device is mounted by stretching it and covering it with a delivery sheath; the distal edge is protected beneath a capture coil. The device's metal coverage depends heavily on the method of deployment (pushing vs unsheathing) and also on vessel tortuosity if the devices are telescoped. For example, a 4.75-mm PED in a 5-mm vessel has approximately $27 \% \pm$ $4 \%$ metal coverage. The same device in a $3-\mathrm{mm}$ vessel has only $18 \% \pm 3 \%$ coverage. As vessel diameter decreases further, the metal coverage increases again. On the other hand, a 4.25-mm PED in a 4.5-mm vessel has $36 \%$ metal coverage due to passive expansion to a $4.5-\mathrm{mm}$ diameter, permitting some frontloading and decreased porosity. ${ }^{80}$ The Pipeline Flex embolization device, a newer generation implant, allows the operator greater flexibility and the ability to resheath up to a certain point (Fig. 1). ${ }^{66}$ Before the Flex device became available, an incorrectly placed Pipeline device would need to be "corked" and pulled into the guide for removal.

Some deployment pearls for PED placement from Shapiro et al.$^{80}$ based on benchtop experiments include the following. 1) Oversizing over a fusiform lesion will lead to a transition zone with less metal coverage distally, which in the smaller artery can produce a lip/endoleak. No degree of loading will resolve this. Two devices are necessary. 2) Oversizing with a small landing zone can lead to the device edges assuming a conical appearance. If the device is deployed under tension, foreshortening with prolapse into the aneurysm can occur.

The Pipeline Flex is typically deployed through a 0.027inch ID (inner diameter) microcatheter such as Marksman (Covidien/Medtronic), Headway 27 (Microvention), or Phenom (Medtronic). Some surgeons use an intermediate support catheter for stability. In tortuous anatomy, a larger guide catheter is also used. PED deployment can be complicated by torsion and failed device opening, as well as stretching of the microcatheter in tortuous anatomy. The best strategy for managing torsion is early recognition and prevention. If it occurs, "swaging" the PED by moving the catheter back and forth may help with different amounts of loading and stretching. Incomplete opening or failed opening maneuvers include, as a last resort, intraDIC (distal intracranial catheter) deployment or utilizing 

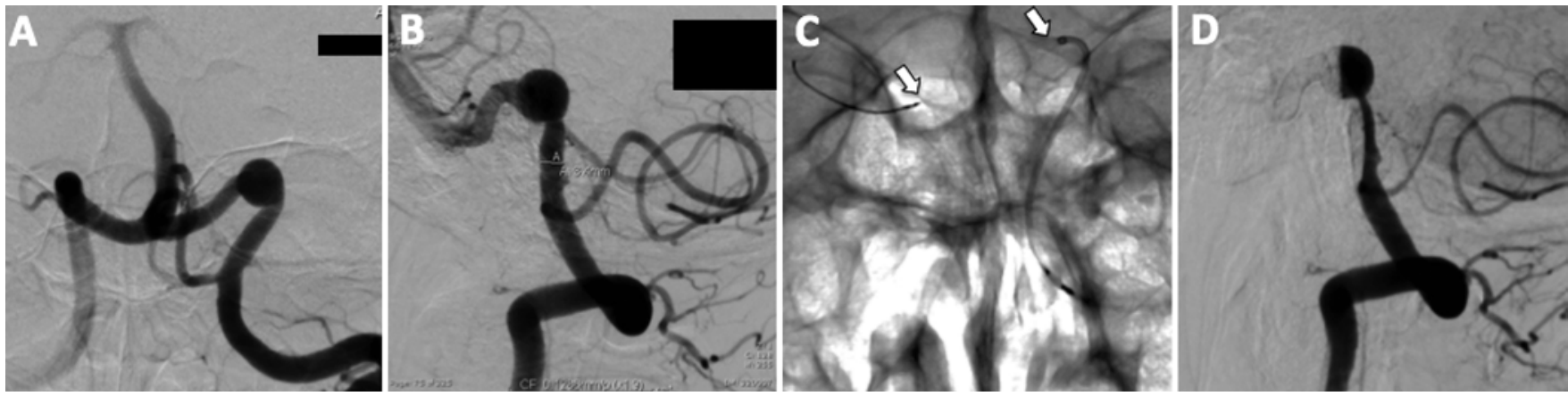

FIG. 1. Pipeline Flex. A and B: Anteroposterior (AP) and lateral angiograms ( $A$ and $B$, respectively) of a left VA injection demonstrating a $V A\left(V_{4}\right.$ segment) aneurysm in a patient presenting with posterior circulation stroke. C: AP radiograph demonstrating partial deployment of a PED (arrows). D: Left VA lateral-view angiogram obtained immediately after PED placement demonstrating intraaneurysmal flow stasis.

an intermediate catheter to open a stretched device. ${ }^{54} \mathrm{Bal}-$ loon angioplasty within the partially expanded PED may be required.

The PITA study (The Pipeline Embolization Device for the Intracranial Treatment of Aneurysms), ${ }^{63}$ the first multicenter prospective trial of PED treatment, studied 31 aneurysms, predominantly involving the proximal and distal cavernous ICA (mean aneurysm size $11.5 \mathrm{~mm}$, mean neck diameter $5.8 \mathrm{~mm}$ ). Fifteen lesions were treated with PED alone, while another 15 were treated with coils and PED. The occlusion rate was $93 \%$ at 6 months with 2 major strokes. The PUFS study (Pipeline for Uncoilable or Failed Aneurysms) $)^{3}$ prospectively assessed 107 patients with a mean aneurysm size of $18 \mathrm{~mm} ; 20 \%$ of the aneurysms were giant. The aneurysm occlusion rate was $73 \%$ at 180 days with a major stroke rate of 5.6\%. Recently, the PUFS 3-year follow-up results were released by Becske et al. ${ }^{4}$ At 3 years after treatment, 74 patients had undergone follow-up angiography, which showed complete angiographic occlusion in $93.4 \%$. Of the 103 surviving patients, 85 underwent functional outcome assessment, and 80 of these patients had modified Rankin Scale scores of 0-1. No recanalization of previously occluded PED-treated aneurysms was noted over 3 years. Five aneurysms required retreatment. This study reported a $2.6 \%$ delayed aneurysm or device-related serious adverse event rate, with no lasting neurological sequelae. The authors concluded that
PED was safe and effective for complex large and giant aneurysms of the ICA. Furthermore, the device led to progressive vascular remodeling, with high rates of complete occlusion on longer-term follow-up.

Numerous other groups have reported their experience with PED use. Recently, the long-term results of the Buenos Aires experience with flow diversion were published. In their series of 1000 patients, 633 patients were treated with PED. A history of subarachnoid hemorrhage was present in $18.5 \%$ all study participants. Eight-year followup demonstrated $100 \%$ aneurysm occlusion. A $98 \%$ technical success rate was reported, along with a $5.9 \%$ periprocedural morbidity and mortality rate..$^{57}$ The Barcelona ${ }^{83}$ and Canadian ${ }^{64}$ experiences with PED for aneurysms also demonstrated positive results.

The device has also been used in off-label applications for distal lesions, with one study reporting an occlusion rate of $84 \%$ following PED treatment of MCA aneurysms..$^{91}$ Distal anterior cerebral artery aneurysms are also amenable to treatment with PED. ${ }^{55}$ PED uses for small anterior circulation aneurysms have also shown good occlusion rates, with risk profiles similar to those for stentassisted coiling. ${ }^{18}$

\section{Surpass}

The Surpass flow diverter is a self-expandable braided tubular structure composed of cobalt-chromium $(30 \%$
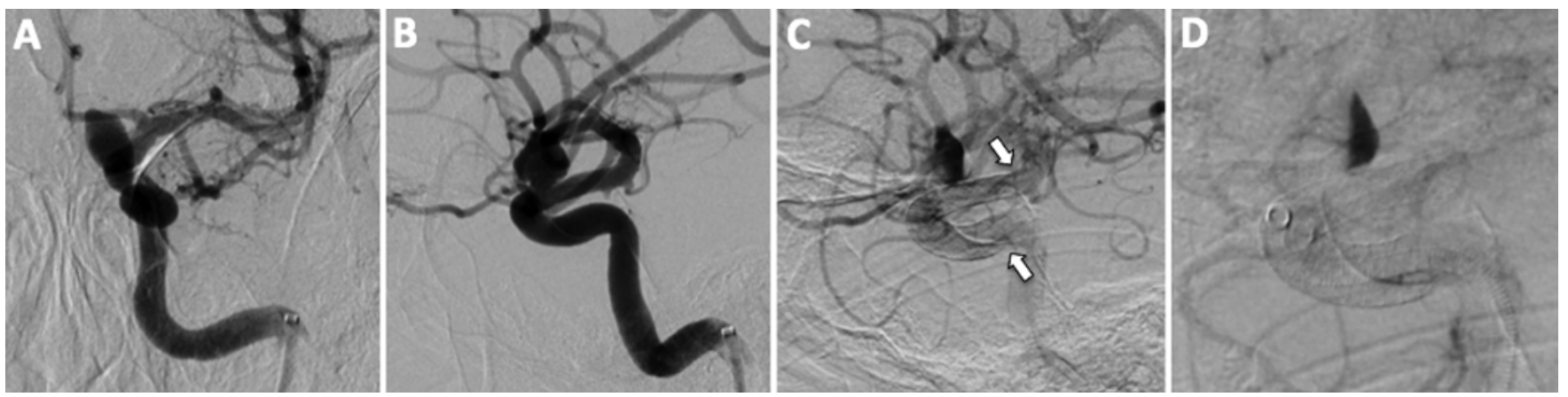

FIG. 2. Surpass embolization device. A and B: AP and lateral angiograms of a left ICA injection demonstrating a paraclinoid aneurysm in a patient who presented with blurry vision in the left eye. C: AP radiograph demonstrating complete deployment of a Surpass device (arrows). D: Left ICA lateral-view angiogram obtained immediately after Surpass device placement demonstrating intraaneurysmal flow stasis. 

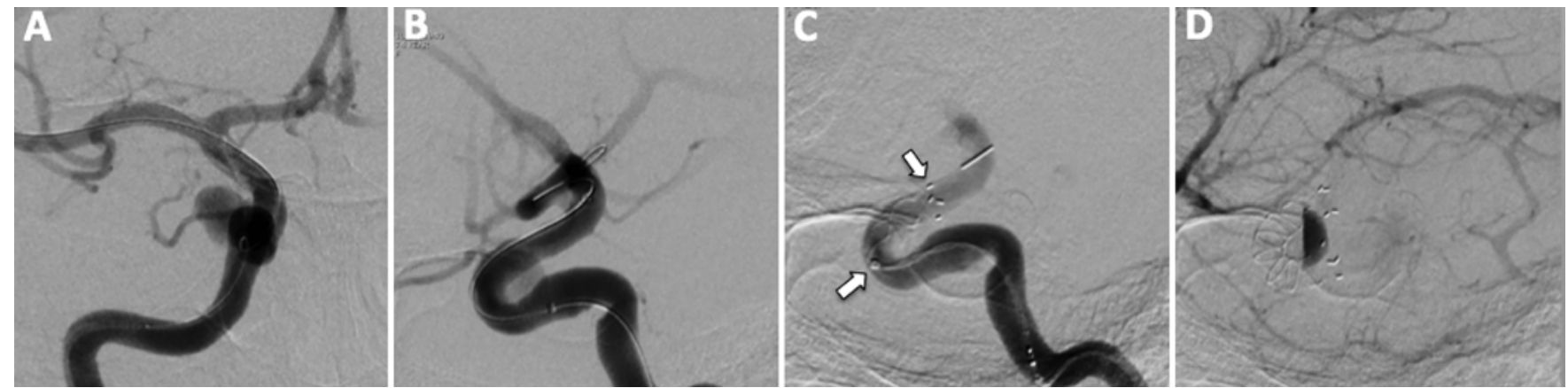

FIG. 3. FRED. A and B: AP and lateral angiograms of a right ICA injection demonstrating a paraclinoid aneurysm in a patient with headaches. C: AP radiograph demonstrating partial FRED deployment (arrows). D: Right ICA lateral-view angiogram obtained immediately after FRED placement demonstrating intraaneurysmal flow stasis.

metal coverage) (Fig. 2). The longest device is $50 \mathrm{~mm}$, and the widest $5.3 \mathrm{~mm}$. While the $2-\mathrm{mm}$ device has 48 braided wires, the 3- to 4-mm devices have 72 braided wires, and the 5-mm device has 96 wires, providing a more uniform pore density over different sizes. In addition, the filament sizes change from 25 to $36 \mu \mathrm{m}$, depending on the device diameter. The braid angle was especially designed to prevent changes in mesh density around curves and also to minimize foreshortening (Fig. 2) ${ }^{87}$ The device is resheathable up to $11 \mathrm{~mm}$ between catheter tip and pusher. The Surpass device is loaded within a 3.7-Fr distal catheter with a pusher catheter and accepts a 0.014-inch microguidewire. Experienced neurointerventionalists and neurosurgeons have found this Surpass device technically easier to deploy than other flow diverters.

In a multicenter trial by Wakhloo et al. ${ }^{87} 165$ patients with anterior and posterior circulation aneurysms were treated with Surpass with a 98\% technical success rate and an average of 1.05 devices per aneurysm. At follow-up, $75 \%$ of aneurysms showed complete occlusion. The rates of permanent neurological morbidity and mortality were $6 \%$ and $2.7 \%$, respectively. The incidence rate for ischemic stroke within 30 days was $3.7 \%$, and the incidence rate for intraparenchymal hematoma at less than 7 days was $2.5 \%$. Dilatation was required after device placement in $19 \%$ of cases due to inadequate intimal apposition. Guidewire perforation occurred in $3.1 \%$ of cases. In another cohort of 20 patients with large ICA aneurysms $(>10 \mathrm{~mm})$ and tortuous anatomy of the arch or cervical/cavernous ICA, Surpass device placement was successful, demonstrating navigability. ${ }^{23}$ The Surpass device is being studied in an ongoing clinical trial (the Surpass Intracranial Aneurysm Embolization System Pivotal Trial to Treat Large or Giant Wide Neck Aneurysms [SCENT], clinicaltrials.gov registration no. NCT01716117).

\section{FRED}

The FRED (flow redirection endoluminal device) differs significantly in design from the 2 previously described flow diverters, being a self-expanding dual-layer braided construct, or a stent within a stent. The inner layer has low porosity (48 braided nitinol wires), while the outer layer has high porosity (16 nitinol wires). An interwoven tantalum layer provides radiopacity and connects the inner and outer layers. The inner and outer layers are only present over the central $80 \%$ of the device. Sizes range from 3.5 to $5.5 \mathrm{~mm}$ and lengths from 7 to $56 \mathrm{~mm}$. Resheathing is possible until $80 \%$ of the device is unsheathed (Fig. 3). An 0.027-inchID microcatheter is used for deployment. ${ }^{61}$ Möhlenbruch et al. ${ }^{61}$ examined 29 patients with 34 aneurysms that had been treated with FRED placement. The technical success rate for device placement was $100 \%$. At 6-month follow-up, 22 of 30 aneurysms were occluded. There was 1 disabling stroke and 2 minor strokes. Another study of 37 patients noted a $3 \%$ procedural complication rate. At follow-up, fish-mouthing or foreshortening of the device was found to have occurred in 5 patients. The rate of aneurysm occlusion was $32 \%$ at $0-1$ month and $100 \%$ (8 of 8 cases) at 7-12 months ${ }^{46}$ A single-center study from Italy noted complete occlusion in 20 of 24 aneurysms treated with the FRED system and intraprocedural and postprocedural complication rates of $4 \%$ and $12 \%$, respectively. ${ }^{9}$ An ongoing study of FRED is under way (Pivotal Study of the MicroVention Flow Re-Direction Endoluminal Device [FRED] Stent System in the Treatment of Intracranial Aneurysms, clinicaltrials.gov registration no. NCT01801007).

\section{SILK}

The SILK flow-diverting device is a flexible self-expanding tubular structure composed of braided mesh with flared ends. The device is composed of 48 nickel-titanium (nitinol) and platinum microfilaments roughly $35 \mu \mathrm{m}$ in size and was designed to provide $35 \%-55 \%$ metal coverage with a pore size of $110-250 \mu \mathrm{m}$ at the nominal diameter. ${ }^{47}$

A systematic review ${ }^{62}$ of SILK flow-diverter cases found 285 patients reported on in the literature; $86 \%$ of their aneurysms were anterior circulation lesions, and $44 \%$ and $17 \%$ of aneurysms were classified as large or giant, respectively. Ischemic complications occurred in $10 \%$ of patients, and the aneurysm rupture rate was $3.5 \%$, with a cumulative mortality of $4.9 \%$. The 12-month aneurysm occlusion rate was $81 \%$. The authors concluded that the SILK device achieves high rates of occlusion but may carry higher rates of ischemic injury and mortality. ${ }^{62} \mathrm{~A}$ recently published Canadian study ${ }^{79}$ of 92 SILK-treated cases noted $83 \%$ complete or near-complete occlusion at last followup. Aneurysm size ranged from 2 to $60 \mathrm{~mm}$. The perioperative morbidity and mortality rates were $8.7 \%$ and $2.2 \%$, respectively. The authors concluded that the SILK flow 
TABLE 2. Summary of characteristics of intrasaccular flow diverters

\begin{tabular}{lllll}
\hline Device & \multicolumn{1}{c}{ Design } & Retrievable & Deployment & Detachment \\
\hline Medina & $\begin{array}{c}\text { Self-expanding, 3D, alloy mesh w/ shape memory that } \\
\text { assumes a spherical shape }\end{array}$ & Yes, similar to coils & Microcatheter w/ 0.021-inch ID & Mechanical \\
\hline WEB & $\begin{array}{c}\text { Self-expanding, braided, nitinol wires w/ platinum markers } \\
\text { forming a cylinder (SL) or sphere-like (SLS) device }\end{array}$ & Yes & Microcatheter w/ $\geq 0.027$-inch ID & Electrothermal \\
\hline LUNA & $\begin{array}{l}\text { Double-layer self-expanding, ovoid ball implant; nitinol w/ } \\
\text { platinum markers }\end{array}$ & Yes & Microcatheter w/ $\geq 0.027$-inch ID & Operator activation \\
of delivery handle
\end{tabular}

diverter is an important tool for complex aneurysms, but complication rates remain a problem. They did go on to say, however, that complication rates should be assessed in the context of available alternatives. Another recent study of complex intracranial aneurysms concluded that SILK is a good treatment option for anterior circulation lesions, but additional stents may be required due to the low opening force of SILK. The authors also stated that treatment of large posterior circulation aneurysms with SILK flow diverters carries a high rate of severe complications. ${ }^{81}$ An earlier study of 12 patients with basilar aneurysms undergoing SILK placement noted 1 case of acute basilar occlusion and 3 cases of delayed neurological events at a mean of 16 weeks. The authors concluded that SILK device placement in the basilar artery is feasible and well tolerated in most, but late ischemic events do occur, and the device should be reserved for otherwise untreatable lesions. ${ }^{47}$ Two studies assessed both PED and SILK and found comparable morbidity and clinical outcomes. ${ }^{10,59}$ Ongoing studies include the MARCO POLO postmarket clinical investigation (Multicenter Randomized Trial on Selective Endovascular Aneurysm Occlusion with Coils versus Parent Vessel Reconstruction with the SILK Flow Diverter, www.clinicaltrials.gov registration no. NCT01084681).

\section{p64}

The p64 flow-modulation device allows full deployment with recoverability. The device is composed of 64 braided nitinol wires. It is delivered via a 0.027 -inch-ID microcatheter, and once unsheathed, is mechanically detached. The diameter ranges from 2.5 to $5 \mathrm{~mm}$ and the length from 12 to $36 \mathrm{~mm}$. Detachment occurs in 4 steps once the device is positioned: Step 1, peel-away sheath is removed; Step 2, white torque is loosened; Step 3, another torque is placed proximal to the detachment tubing and tightened to the delivery wire; and Step 4, detachment is completed by pulling the proximal end of the polymer tube toward the torque. The p64 device is deployed via wire pushing and catheter unsheathing. ${ }^{7}$

The detachment mechanism was validated in a small series of 6 aneurysms, demonstrating 100\% success in immediately reducing aneurysm inflow with all devices.? There was no morbidity or mortality. In a larger series of 121 patients treated with p64, complete occlusion was seen in $79 \%$ of followed lesions at 9 months posttreatment. Late follow-up showed complete occlusion in 30 of 35 lesions at a median follow-up period of 496 days. The rates of transient and permanent morbidity were $5 \%$ and $1.7 \%$, respectively, and the mortality rate was $0.8 \% .^{30}$ A recent study of 40 patients treated with p64 reported complete occlu- sion in $88 \%$, permanent morbidity in $2.5 \%$ due to in-stent thrombosis, and technical complications in $16 \%{ }^{8}$

\section{Intrasaccular Flow Diversion/Disruption}

Intrasaccular devices, as a group, provide high metal coverage at the aneurysm neck, but unlike the endoluminal flow-diversion devices, these devices are placed within the aneurysm itself. A theoretical advantage is possibly a decreased need (or no need) for adjunct antiplatelet therapy. See Table 2 for a tabular comparison of these devices.

\section{Woven EndoBridge}

The Woven EndoBridge (WEB) device (Sequent Medical) is an endosaccular/intrasaccular flow diverter/disrupter composed of braided nitinol wires with proximal and distal platinum markers (Fig. 4). The wire mesh spanning the aneurysm inflow provides $35 \%-45 \%$ metal coverage. The device has an inner and outer wire mesh, forming 2 compartments. The stent-like structure of the device provides adherence to the aneurysm wall (Fig. 4). The device is deployed in a manner similar to available stents or coils and has an electrothermal detachment system. ${ }^{26,68}$ The WEB device comes in 2 configurations: standard (SL, "single layer") and spherical (SLS, "single layer sphere"). The WEB SL is available in a diameter range of 4-11 mm and a height range of 3-9 $\mathrm{mm}$.

The initial clinical experience with WEB was reported in 2011 after implantation into unruptured basilar artery apex and MCA trifurcation aneurysms. Short-term angiographic follow-up at 8 weeks posttreatment revealed complete aneurysm occlusion. ${ }^{45}$ Results from a multicenter tri$\mathrm{al}^{69}$ including 20 patients showed $80 \%$ adequate occlusion of wide-necked aneurysms at 2-8 months. One patient experienced transient worsening due to a thromboembolic event, and $23.8 \%$ of patients underwent additional stent or coil placement. This study also had 1 inadvertent WEB deployment. Lubicz et al. ${ }^{56}$ examined WEB for treatment of wide-necked bifurcation aneurysms and noted successful deployment in 18 of 19 patients and improved or stable follow-up angiography in all but 4 cases. Pierot et al. ${ }^{68}$ treated $34 \mathrm{MCA}$ aneurysms with WEB; $85 \%$ of the aneurysms were unruptured, and neck sizes were $4 \mathrm{~mm}$ or greater in $88 \%$ of cases. The WEB device was used exclusively for $88 \%$ of aneurysms. One intraoperative rupture was noted in this study. At 2-12 months' follow-up, 83\% of aneurysms had adequate occlusion (total occlusion or neck remnant). There was a $15.6 \%$ thromboembolism rate, prompting commentary regarding the need for antiplatelet agents, given the amount of metal coverage at the aneu- 

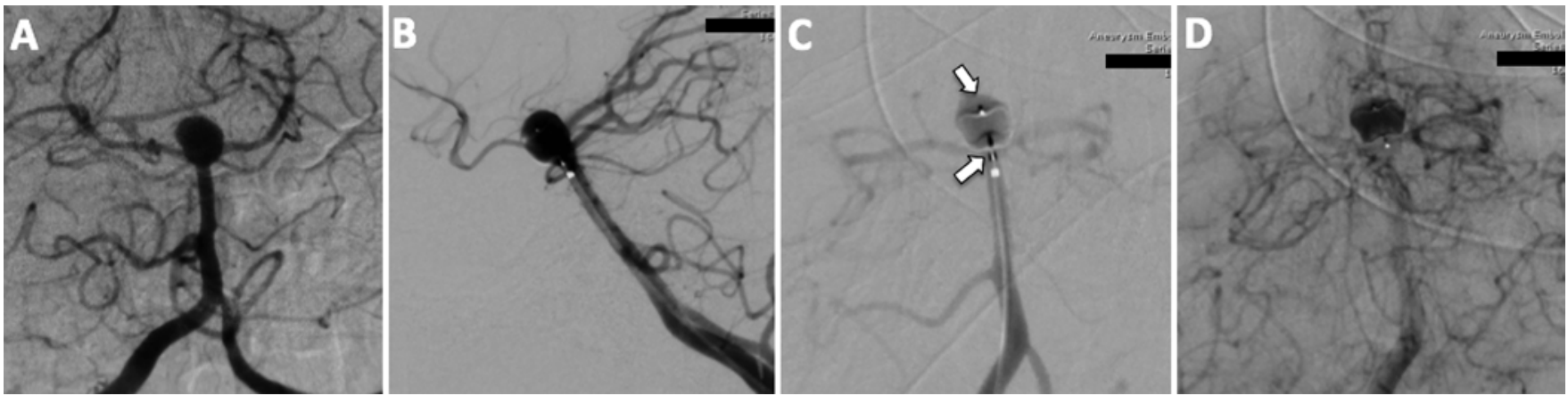

FIG. 4. WEB. A and B: AP and lateral angiogram of a right VA injection demonstrating a basilar tip aneurysm in a patient with headaches. C: AP radiograph demonstrating complete deployment of a WEB device (arrows). D: Right VA lateral-view angiogram obtained immediately after WEB placement demonstrating intraaneurysmal flow stasis.

rysm neck. In 2016, the WEBCAST (WEB Clinical Assessment of Intrasaccular Aneurysm Therapy) ${ }^{67}$ study was published, including 51 patients at multiple centers. Treatment with WEB was achieved in $94 \%$ of patients; the rate of thromboembolic events was $17.6 \%$, with a permanent deficit in 1 patient. One patient died, but this death was related to the patient's ruptured aneurysm status on entry into the study. Success (stable neck remnant or complete occlusion and no worsening in angiographic appearance) at 6 months was achieved in $85 \%$ of patients. The WEBCAST $2^{70}$ study evaluating the second-generation device (SL and SLS) reported $79 \%$ overall adequate occlusion on follow-up, with 1-month morbidity and mortality rates of $1.8 \%$ and $0 \%$, respectively. Van Rooij et al ${ }^{86}$ used WEB in 32 ruptured aneurysms with an average size of $4.9 \mathrm{~mm}$ and wide necks in $75 \%$ of cases. No adjunctive stents or other devices were used. Three thromboembolic events occurred; only 1 patient developed an infarction. The procedural complication rate was $3 \%$. Seven patients died due to sequelae of the subarachnoid hemorrhage. Follow-up angiography was performed at 3 months in 18 cases and revealed that $16(89 \%)$ of 18 aneurysms were occluded. No rehemorrhages occurred during follow-up, and the authors concluded that WEB was safe and effective for small, ruptured aneurysms without adjunctive devices or anticoagulation. Clajus et al. ${ }^{20}$ reported on 108 consecutive WEB placements; $41 \%$ were in ruptured aneurysms. Rerupture after WEB implantation was detected in 2 aneurysms, both in patients who had presented with subarachnoid hemorrhage. The authors reported a $10 \%$ thromboembolic rate and a $75 \%$ adequate occlusion rate; $15 \%$ of the aneurysms required retreatment.

\section{LUNA AES}

The LUNA AES (aneurysm embolization system) is a self-expanding double-layer nitinol mesh with platinum markers. The device is delivered via a standard 0.027-inch microcatheter and takes an ovoid shape within the aneurysm. ${ }^{51}$

Piotin et al ${ }^{73}$ reported in 2012 a small prospective clinical study involving 15 patients with 14 unruptured and 1 ruptured saccular aneurysms. The aneurysm size was between 5-6.7 $\mathrm{mm}$, and the aneurysms were distributed as follows: paraophthalmic (5 cases), anterior choroidal (3), posterior communicating (3), middle cerebral (2), internal carotid (1), and anterior cerebral artery (1). There was 1 failed procedure, 1 failed detachment, 4 balloon-assisted deployments, 1 rupture, and 1 thromboembolic event. In 2014, Piotin et al..$^{71}$ reported LUNA AES results for 63 patients treated at 9 European centers. At 12 months $(\mathrm{n}=$ 31 ), complete occlusion was observed in $38.7 \%$ and nearcomplete occlusion in $32.2 \%$. Periprocedural safety events were noted in $6.25 \%$ of cases and included occlusion of the parent artery with LUNA and cavernous rupture during LUNA delivery. The overall mortality rate was $0 \%$, and at 6 months' posttreatment there were no safety events. In 2015, the 12-month follow-up results of the European LUNA study ${ }^{72}$ were reported. Most aneurysms were unruptured bifurcation or terminal aneurysms less than 10 $\mathrm{mm}$ in maximum diameter. A total of 63 patients were included; 35 adverse events occurred in 21 patients, with 24 events being classified as serious. Adjunctive devices were used in 6 cases. Angiographic follow-up at 12 months ( $\mathrm{n}=$ 44) revealed a $77 \%$ rate of complete or near-complete occlusion. The authors concluded that the 12-month results demonstrated a good safety profile and good results on angiographic follow-up.

\section{Medina}

The Medina embolic device (Medtronic) is a 3D coil made from shape-set core wire with shape-set alloy outer filaments forming petals. The coil is deployed linearly through a microcatheter but assumes a spherical shape within the aneurysm, providing neck coverage with the petals and stable intrasaccular structure with its 3D shape. It is available in framing and filling styles. ${ }^{85}$

Turk et al.$^{85}$ reported an early human experience in 5 patients (9 aneurysms) in 2016. An early clinical experience involving 15 patients with at least 5-mm aneurysm fundi was reported in 2017. ${ }^{\text {The }}$ The authors reported successful deployment in all but 1 case and the need for adjunctive devices in 10 cases. There were 3 complications, but none could be attributed to the device. Follow-up angiography in 11 patients showed complete aneurysm exclusion in 4 patients, stable neck remnants in 6 patients, and an enlarging neck remnant in 1 patient. The authors raised several good points regarding the limitations of Medina as an intrasaccular flow diverter. First, many aneurysms are not spherical and/or have blebs. It is sometimes necessary to use adjunctive devices to coil blebs (to stabilize the device 
and prevent bleb rupture from a poorly placed device that could direct flow toward the bleb) or use interval endoluminal flow diversion for neck remnants. Second, if they are considering using both endoluminal and intrasaccular flow diversion, the authors do not use many Medina coils, as this can lead to increased thrombogenicity. ${ }^{1}$

\section{Antiplatelet Therapy and Flow Diversion}

We typically use dual-antiplatelet therapy with aspirin $325 \mathrm{mg}$ and clopidogrel $75 \mathrm{mg}$ for 5 days before the procedure and find that this results in therapeutic levels on platelet function tests for endoluminal flow-diverter placement. If therapeutic levels are not achieved with this treatment, we will administer a loading dose and recheck levels prior to proceeding. We rarely use glycoprotein IIb/IIIa $(\mathrm{GpIIb} /$ IIIa) inhibitors up front; typically they are reserved for patients with acute in-stent thrombosis. We continue aspirin treatment indefinitely, and clopidogrel treatment is typically stopped around 6 months unless the patient was already taking this medication for another reason. Both the PUFS $^{3}$ and PITA $^{63}$ studies used dual-antiplatelet therapy in their PED treatment protocol. Recently, however, the need for dual-antiplatelet therapy has been called into question. Colby et al..$^{21}$ reported an $8 \%$ rate of transient neurological deficits, with no permanent deficits, after treatment with GpIIb/IIIa inhibitors for patients undergoing PED placement who were clopidogrel hyporesponders (P2Y12 reaction units $>200$ ). The authors suggested a diminutive role for clopidogrel in preventing thromboembolic events in PED cases. The first reported PED with Shield Technology was recently placed for a ruptured dissecting aneurysm of the VA with only aspirin and a single loading dose of a GpIIb/IIIa inhibitor. ${ }^{19}$ Shield Technology (Medtronic) is under study for the PED to reduce thrombogenicity. Shield Technology is a phosphorylcholine coating that through molecular mimicry was designed to decrease thrombogenicity and hopefully decrease or alleviate the need for antiplatelet agents. ${ }^{33}$ Other options for ruptured aneurysms include preprocedural aspirin followed by clopidogrel loading at the conclusion of the procedure. Use of this regimen has also been reported for stent-assisted coiling in acute treatment of ruptured aneurysms. ${ }^{82}$ In a recent survey of academic cerebrovascular neurosurgeons, $100 \%$ of survey respondents reported using dual-antiplatelet therapy with aspirin and clopidogrel as their first-line choice; $42.3 \%$ of responders indicated that they used aspirin and ticagrelor for clopidogrel hypo- or nonresponders, and the same percentage indicated that they used aspirin and prasugrel in such cases. ${ }^{36}$

Intrasaccular flow diversion was designed with the intended advantage of not requiring dual-antiplatelet therapy, given that the parent vessel is exposed to less metal than with endoluminal devices. However, Pierot et al. ${ }^{68}$ noted a $15.6 \%$ thromboembolism rate for intrasaccular flow disruption with the WEB device in MCA aneurysms. All 5 thromboembolic events occurred in patients who were either not treated with any antiplatelet medication or treated with only 1 antiplatelet medication; 3 of the events were noted intraoperatively and treated with thrombolytics. This finding led to expert commentary as noted above, suggesting consideration of dual-antiplatelet therapy given the amount of metal at the aneurysm neck. For comparison's sake, commonly quoted ranges for stroke rates during aneurysm coiling are $2 \%-9 \%$, and higher for asymptomatic events.$^{65}$ This has led some groups to perform platelet function tests for elective aneurysm coiling and stratify patients to different regimens depending on the results. ${ }^{2}$

\section{Future Directions and Limitations}

While long-term data are becoming available for PEDtreated aneurysms, there is still a lack of long-term data on aneurysms treated with other types of flow diversion, both endoluminal and intrasaccular. More randomized studies with long-term follow-up will be needed to determine if all types of flow diversion ultimately lead to a lasting cure. New flow diverters continue to be designed and developed, with FloWise, another flow diverter, being tested in animal models recently. ${ }^{44}$ Ultimately, comparative studies of each flow diverter versus each of the others will be needed to determine if niches are better suited to certain devices or if one device is safer than another. In addition, the combination of intrasaccular and endoluminal flow diversion will need to be better explored. Lastly, the application of flow diverters to ruptured aneurysms will only become commonplace if these devices achieve a low incidence of thrombogenicity. The PREMIER study (Prospective Study on Embolization of Intracranial Aneurysms with Pipeline Embolization Device, clinicaltrials.gov registration no. NCT02186561) is currently under way and was designed to expand the current indication of PED use from ICA aneurysms proximal to the posterior communicating artery to include posterior circulation aneurysms and those aneurysms distal to the posterior communicating segment of the ICA.

\section{Conclusions}

Flow diversion, both endoluminal and intrasaccular, represents a cutting-edge treatment for intracranial aneurysms that is quickly becoming the standard of care for many types of aneurysms and vascular disease. While long-term data on the PED are becoming more available and promising, more studies are needed to validate the long-term treatment value of other existing devices and new devices to come.

\section{References}

1. Aguilar Perez M, Bhogal P, Martinez Moreno R, Bäzner H, Ganslandt O, Henkes H: The Medina Embolic Device: early clinical experience from a single center. J Neurointerv Surg 9:77-87, 2017

2. Awad AJ, Kellner CP, Mascitelli JR, Fifi JT, Bederson JB, Mocco J: Modified antiplatelet regimen trial for elective coil embolization for unruptured intracranial aneurysms. World Neurosurg 90:684, 2016

3. Becske T, Kallmes DF, Saatci I, McDougall CG, Szikora I, Lanzino G, et al: Pipeline for uncoilable or failed aneurysms: results from a multicenter clinical trial. Radiology 267:858868,2013

4. Becske T, Potts MB, Shapiro M, Kallmes DF, Brinjikji W, Saatci I, et al: Pipeline for uncoilable or failed aneurysms: 3 -year follow-up results. J Neurosurg [epub ahead of print October 14, 2016. DOI: 10.3171/2015.6.JNS15311]

5. Berge J, Tourdias T, Moreau JF, Barreau X, Dousset V: Peri- 
aneurysmal brain inflammation after flow-diversion treatment. AJNR Am J Neuroradiol 32:1930-1934, 2011

6. Brasiliense LB, Stanley MA, Grewal SS, Cloft HJ, Sauvageau E, Lanzino G, et al: Silent ischemic events after Pipeline embolization device: a prospective evaluation with MR diffusion-weighted imaging. J Neurointerv Surg 8:1136-1139, 2016

7. Briganti F, Leone G, Marseglia M, Cicala D, Caranci F, Maiuri F: p64 Flow Modulation Device in the treatment of intracranial aneurysms: initial experience and technical aspects. J Neurointerv Surg 8:173-180, 2016

8. Briganti F, Leone G, Ugga L, Marseglia M, Macera A, Manto A, et al: Mid-term and long-term follow-up of intracranial aneurysms treated by the p64 Flow Modulation Device: a multicenter experience. J Neurointerv Surg 9:70-76, 2017

9. Briganti F, Leone G, Ugga L, Marseglia M, Solari D, Caranci F, et al: Safety and efficacy of flow re-direction endoluminal device (FRED) in the treatment of cerebral aneurysms: a single center experience. Acta Neurochir (Wien) 158:17451755,2016

10. Briganti F, Napoli M, Tortora F, Solari D, Bergui M, Boccardi E, et al: Italian multicenter experience with flow-diverter devices for intracranial unruptured aneurysm treatment with periprocedural complications - a retrospective data analysis. Neuroradiology 54:1145-1152, 2012

11. Brinjikji W, Lanzino G, Cloft HJ, Siddiqui AH, Boccardi E, Cekirge S, et al: Risk factors for ischemic complications following Pipeline embolization device treatment of intracranial aneurysms: results from the IntrePED study. AJNR Am J Neuroradiol 37:1673-1678, 2016

12. Brinjikji W, Lanzino G, Cloft HJ, Siddiqui AH, Kallmes DF: Risk factors for hemorrhagic complications following pipeline embolization device treatment of intracranial aneurysms: results from the international retrospective study of the Pipeline embolization device. AJNR Am J Neuroradiol 36:2308-2313, 2015

13. Brinjikji W, Murad MH, Lanzino G, Cloft HJ, Kallmes DF: Endovascular treatment of intracranial aneurysms with flow diverters: a meta-analysis. Stroke 44:442-447, 2013

14. Byrne JV, Szikora I: Flow diverters in the management of intracranial aneurysms: a review. EJMINT 2012:1225000057, 2012

15. Casasco AE, Aymard A, Gobin YP, Houdart E, Rogopoulos A, George B, et al: Selective endovascular treatment of 71 intracranial aneurysms with platinum coils. J Neurosurg 79:3-10, 1993

16. Chalouhi N, Chitale R, Starke RM, Jabbour P, Tjoumakaris $S$, Dumont AS, et al: Treatment of recurrent intracranial aneurysms with the Pipeline embolization device. J Neurointerv Surg 6:19-23, 2014

17. Chalouhi N, Daou B, Starke RM, Barros G, Tjoumakaris S, Rosenwasser R, et al: The Pipeline embolization device: midterm results and predictors of outcomes in 335 consecutive patients. Stroke 47:A8-A8, 2016

18. Chalouhi N, Starke RM, Yang S, Bovenzi CD, Tjoumakaris $\mathrm{S}$, Hasan D, et al: Extending the indications of flow diversion to small, unruptured, saccular aneurysms of the anterior circulation. Stroke 45:54-58, 2014

19. Chiu AHY, Ramesh R, Wenderoth J, Davies M, Cheung A: Use of aspirin as sole oral antiplatelet therapy in acute flow diversion for ruptured dissecting aneurysms. J Neurointerv Surg [epub ahead of print], 2016

20. Clajus C, Strasilla C, Fiebig T, Sychra V, Fiorella D, Klisch $\mathrm{J}$ : Initial and mid-term results from 108 consecutive patients with cerebral aneurysms treated with the WEB device. J Neurointerv Surg 9:411-417, 2017

21. Colby G, Lin L, Lubelski D, Bender M, Xu R, Jiang B, et al: $\mathrm{P}-016$ Successful flow diversion of cerebral aneurysms in Plavix hyporesponders (PRU $\geq 200$ ): an argument for anti- platelet monotherapy? J Neurointerv Surg 8:A35-A35, 2016 (Abstract)

22. Colby GP, Lin LM, Caplan JM, Jiang B, Huang J, Tamargo $\mathrm{RJ}$, et al: Immediate procedural outcomes in 44 consecutive Pipeline Flex cases: the first North American single-center series. J Neurointerv Surg 8:702-709, 2016

23. Colby GP, Lin LM, Caplan JM, Jiang B, Michniewicz B, Huang J, et al: Flow diversion of large internal carotid artery aneurysms with the surpass device: impressions and technical nuance from the initial North American experience. J Neurointerv Surg 8:279-286, 2016

24. Dabus G, Grossberg JA, Cawley CM, Dion JE, Puri AS, Wakhloo AK, et al: Treatment of complex anterior cerebral artery aneurysms with Pipeline flow diversion: mid-term results. J Neurointerv Surg 9:147-151, 2017

25. Daou B, Starke RM, Chalouhi N, Tjoumakaris S, Hasan D, Khoury J, et al: Pipeline embolization device in the treatment of recurrent previously stented cerebral aneurysms. AJNR Am J Neuroradiol 37:849-855, 2016

26. Ding YH, Lewis DA, Kadirvel R, Dai D, Kallmes DF: The Woven EndoBridge: a new aneurysm occlusion device. AJNR Am J Neuroradiol 32:607-611, 2011

27. Durst CR, Hixson HR, Schmitt P, Gingras JM, Crowley RW: Endovascular treatment of a fusiform aneurysm at the M3-M4 junction of the middle cerebral artery using the Pipeline embolization device. World Neurosurg 86:511.e1-511.e4, 2016

28. Fiorella D, Lylyk P, Szikora I, Kelly ME, Albuquerque FC, McDougall CG, et al: Curative cerebrovascular reconstruction with the Pipeline embolization device: the emergence of definitive endovascular therapy for intracranial aneurysms. J Neurointerv Surg 1:56-65, 2009

29. Fiorella D, Woo HH, Albuquerque FC, Nelson PK: Definitive reconstruction of circumferential, fusiform intracranial aneurysms with the Pipeline embolization device. Neurosurgery 62:1115-1121, 2008

30. Fischer S, Aguilar-Pérez M, Henkes E, Kurre W, Ganslandt $\mathrm{O}$, Bäzner H, et al: Initial experience with p64: a novel mechanically detachable flow diverter for the treatment of intracranial saccular sidewall aneurysms. AJNR Am J Neuroradiol 36:2082-2089, 2015

31. Fischer S, Perez MA, Kurre W, Albes G, Bäzner H, Henkes $\mathrm{H}$ : Pipeline embolization device for the treatment of intraand extracranial fusiform and dissecting aneurysms: initial experience and long-term follow-up. Neurosurgery 75:364374,2014

32. Fischer S, Vajda Z, Aguilar Perez M, Schmid E, Hopf N, Bäzner H, et al: Pipeline embolization device (PED) for neurovascular reconstruction: initial experience in the treatment of 101 intracranial aneurysms and dissections. Neuroradiology 54:369-382, 2012

33. Girdhar G, Li J, Kostousov L, Wainwright J, Chandler WL: In-vitro thrombogenicity assessment of flow diversion and aneurysm bridging devices. J Thromb Thrombolysis 40:437-443, 2015

34. Griessenauer CJ, Ogilvy CS, Foreman PM, Chua MH, Harrigan MR, He L, et al: Pipeline Embolization Device for small intracranial aneurysms: evaluation of safety and efficacy in a multicenter cohort. Neurosurgery 80:579-587, 2017

35. Griessenauer CJ, Ogilvy CS, Foreman PM, Chua MH, Harrigan MR, Stapleton CJ, et al: Pipeline embolization device for small paraophthalmic artery aneurysms with an emphasis on the anatomical relationship of ophthalmic artery origin and aneurysm. J Neurosurg 125:1352-1359, 2016

36. Gupta R, Moore JM, Griessenauer CJ, Adeeb N, Patel AS, Youn R, et al: Assessment of dual-antiplatelet regimen for Pipeline embolization device placement: a survey of major academic neurovascular centers in the United States. World Neurosurg 96:285-292, 2016

37. Higashida RT, Smith W, Gress D, Urwin R, Dowd CF, 
Balousek PA, et al: Intravascular stent and endovascular coil placement for a ruptured fusiform aneurysm of the basilar artery. Case report and review of the literature. J Neurosurg 87:944-949, 1997

38. John S, Bain MD, Hui FK, Hussain MS, Masaryk TJ, Rasmussen PA, et al: Long-term follow-up of in-stent stenosis after Pipeline flow diversion treatment of intracranial aneurysms. Neurosurgery 78:862-867, 2016

39. Kallmes DF, Brinjikji W, Boccardi E, Ciceri E, Diaz O, Tawk R, et al: Aneurysm Study of Pipeline in an Observational Registry (ASPIRe). Interv Neurol 5:89-99, 2016

40. Kallmes DF, Ding YH, Dai D, Kadirvel R, Lewis DA, Cloft HJ: A new endoluminal, flow-disrupting device for treatment of saccular aneurysms. Stroke 38:2346-2352, 2007

41. Kallmes DF, Hanel R, Lopes D, Boccardi E, Bonafé A, Cekirge S, et al: International retrospective study of the Pipeline Embolization Device: a multicenter aneurysm treatment study. AJNR Am J Neuroradiol 36:108-115, 2015 (Erratum in AJNR Am J Neuroradiol 36:E39-E40, 2015)

42. Kan P, Srinivasan VM, Mbabuike N, Tawk RG, Ban VS, Welch BG, et al: Aneurysms with persistent patency after treatment with the Pipeline Embolization Device. J Neurosurg [epub ahead of print September 16, 2016. DOI: 10.3171/2016.6.JNS16402]

43. Kerolus M, Kasliwal MK, Lopes DK: Persistent aneurysm growth following pipeline embolization device assisted coiling of a fusiform vertebral artery aneurysm: a word of caution! Neurointervention 10:28-33, 2015

44. Kim BM, Kim DJ, Kim DI: A new flow-diverter (the FloWise): in-vivo evaluation in an elastase-induced rabbit aneurysm model. Korean J Radiol 17:151-158, 2016

45. Klisch J, Sychra V, Strasilla C, Liebig T, Fiorella D: The Woven EndoBridge cerebral aneurysm embolization device (WEB II): initial clinical experience. Neuroradiology 53:599-607, 2011

46. Kocer N, Islak C, Kizilkilic O, Kocak B, Saglam M, Tureci $\mathrm{E}$ : Flow re-direction endoluminal device in treatment of cerebral aneurysms: initial experience with short-term follow-up results. J Neurosurg 120:1158-1171, 2014

47. Kulcsár Z, Ernemann U, Wetzel SG, Bock A, Goericke S, Panagiotopoulos V, et al: High-profile flow diverter (Silk) implantation in the basilar artery: efficacy in the treatment of aneurysms and the role of the perforators. Stroke 41:16901696,2010

48. Kulcsár Z, Houdart E, Bonafé A, Parker G, Millar J, Goddard AJ, et al: Intra-aneurysmal thrombosis as a possible cause of delayed aneurysm rupture after flow-diversion treatment. AJNR Am J Neuroradiol 32:20-25, 2011

49. Kulcsár Z, Szikora I: The ESMINT retrospective analysis of delayed aneurysm ruptures after flow diversion (RADAR) study. EJMINT 2012:1244000088, 2012

50. Kulcsár Z, Wetzel SG, Augsburger L, Gruber A, Wanke I, Rüfenacht DA: Effect of flow diversion treatment on very small ruptured aneurysms. Neurosurgery 67:789-793, 2010

51. Kwon SC, Ding YH, Dai D, Kadirvel R, Lewis DA, Kallmes DF: Preliminary results of the Luna aneurysm embolization system in a rabbit model: a new intrasaccular aneurysm occlusion device. AJNR Am J Neuroradiol 32:602-606, 2011

52. Lanzino G, Wakhloo AK, Fessler RD, Hartney ML, Guterman LR, Hopkins LN: Efficacy and current limitations of intravascular stents for intracranial internal carotid, vertebral, and basilar artery aneurysms. J Neurosurg 91:538-546, 1999

53. Lieber BB, Livescu V, Hopkins LN, Wakhloo AK: Particle image velocimetry assessment of stent design influence on intra-aneurysmal flow. Ann Biomed Eng 30:768-777, 2002

54. Lin LM, Colby GP, Jiang B, Nundkumar N, Huang J, Tamargo RJ, et al: Intra-DIC (distal intracranial catheter) deployment of the Pipeline embolization device: a novel rescue strategy for failed device expansion. J Neurointerv Surg 8:840-846, 2016

55. Lin N, Lanzino G, Lopes DK, Arthur AS, Ogilvy CS, Ecker $\mathrm{RD}$, et al: Treatment of distal anterior circulation aneurysms with the Pipeline embolization device: a US multicenter experience. Neurosurgery 79:14-22, 2016

56. Lubicz B, Mine B, Collignon L, Brisbois D, Duckwiler G, Strother C: WEB device for endovascular treatment of wideneck bifurcation aneurysms. AJNR Am J Neuroradiol 34:1209-1214, 2013

57. Lundquist J, Ferrario A, Ceratto R, Scrivano E, Chudyk J, Lylyk P: Buenos Aires experience with flow diverter in our first 1000 patients safety, efficacy and long term follow-up. Stroke 47:A12-A12, 2016 (Abstract)

58. Lv X, Yang H, Liu P, Li Y: Flow-diverter devices in the treatment of intracranial aneurysms: a meta-analysis and systematic review. Neuroradiol J 29:66-71, 2016

59. Piano M, Valvassori L, Quilici L, Pero G, Boccardi E: Midterm and long-term follow-up of cerebral aneurysms treated with flow diverter devices: a single-center experience. J Neurosurg 118:408-416, 2013

60. Martin AR, Cruz JP, Matouk CC, Spears J, Marotta TR: The Pipeline flow-diverting stent for exclusion of ruptured intracranial aneurysms with difficult morphologies. Neurosurgery 70 (1 Suppl Operative):21-28, 2012

61. Möhlenbruch MA, Herweh C, Jestaedt L, Stampfl S, Schönenberger S, Ringleb PA, et al: The FRED flow-diverter stent for intracranial aneurysms: clinical study to assess safety and efficacy. AJNR Am J Neuroradiol 36:1155-1161, 2015

62. Murthy SB, Shah S, Shastri A, Venkatasubba Rao CP, Bershad EM, Suarez JI: The SILK flow diverter in the treatment of intracranial aneurysms. J Clin Neurosci 21:203-206, 2014

63. Nelson PK, Lylyk P, Szikora I, Wetzel SG, Wanke I, Fiorella $\mathrm{D}$ : The Pipeline embolization device for the intracranial treatment of aneurysms trial. AJNR Am J Neuroradiol 32:34-40, 2011

64. O'Kelly CJ, Spears J, Chow M, Wong J, Boulton M, Weill A, et al: Canadian experience with the Pipeline embolization device for repair of unruptured intracranial aneurysms. AJNR Am J Neuroradiol 34:381-387, 2013

65. Oxley TJ, Dowling RJ, Mitchell PJ, Davis S, Yan B: Antiplatelet resistance and thromboembolic complications in neurointerventional procedures. Front Neurol 2:83, 2011

66. Pereira VM, Kelly M, Vega P, Murias E, Yilmaz H, Erceg G, et al: New Pipeline Flex device: initial experience and technical nuances. J Neurointerv Surg 7:920-925, 2014

67. Pierot L, Costalat V, Moret J, Szikora I, Klisch J, Herbreteau D, et al: Safety and efficacy of aneurysm treatment with WEB: results of the WEBCAST study. J Neurosurg 124:1250-1256, 2016

68. Pierot L, Klisch J, Cognard C, Szikora I, Mine B, Kadziolka $\mathrm{K}$, et al: Endovascular WEB flow disruption in middle cerebral artery aneurysms: preliminary feasibility, clinical, and anatomical results in a multicenter study. Neurosurgery 73:27-35, 2013

69. Pierot L, Liebig T, Sychra V, Kadziolka K, Dorn F, Strasilla $\mathrm{C}$, et al: Intrasaccular flow-disruption treatment of intracranial aneurysms: preliminary results of a multicenter clinical study. AJNR Am J Neuroradiol 33:1232-1238, 2012

70. Pierot L, Molyneux A, Byrne J: O-020 WEB aneurysm treatment: preliminary results of WEBCAST 2 study. J Neurointerv Surg 8:A13-A14, 2016 (Abstract)

71. Piotin M, Biondi A, Sourour N, Blanc R: O-036 Treatment of intracranial aneurysms with the LUNA AES: midterm clinical and angiographic follow-up. J Neurointerv Surg 6:A19A20, 2014 (Abstract)

72. Piotin M, Biondi A, Sourour N, Mounayer C, Söderman M, 
Andersson T, et al: O-025 The Luna aneurysm embolization system: immediate and 12 month follow-up of the European PMCF study. J Neurointerv Surg 7:A13-A14, 2015 (Abstract)

73. Piotin M, Sourour N, Biondi A, Mounayer C, Blanc R: O-028 The LUNA aneurysm embolization system for treatment of intracranial aneurysms. J Neurointerv Surg 4:A16, 2012 (Abstract)

74. Rangel-Castilla L, Munich SA, Jaleel N, Cress MC, Krishna C, Sonig A, et al: Patency of anterior circulation branch vessels after Pipeline embolization: longer-term results from 82 aneurysm cases. J Neurosurg 126:1064-1069, 2017

75. Rouchaud A, Brinjikji W, Cloft HJ, Kallmes DF: Endovascular treatment of ruptured blister-like aneurysms: a systematic review and meta-analysis with focus on deconstructive versus reconstructive and flow-diverter treatments. AJNR Am J Neuroradiol 36:2331-2339, 2015

76. Roy AK, Grossberg JA, Osbun JW, Skukalek SL, Howard BM, Ahmad FU, et al: Carotid cavernous fistula after Pipeline placement: a single-center experience and review of the literature. J Neurointerv Surg 9:152-158, 2017

77. Sadasivan C, Cesar L, Seong J, Rakian A, Hao Q, Tio FO, et al: An original flow diversion device for the treatment of intracranial aneurysms: evaluation in the rabbit elastaseinduced model. Stroke 40:952-958, 2009

78. Safain MG, Roguski M, Heller RS, Malek AM: Flow diverter therapy with the Pipeline embolization device is associated with an elevated rate of delayed fluid-attenuated inversion recovery lesions. Stroke 47:789-797, 2016

79. Shankar JJS, Tampieri D, Iancu D, Cortes M, Agid R, Krings $\mathrm{T}$, et al: SILK flow diverter for complex intracranial aneurysms: a Canadian registry. J Neurointerv Surg 8:273-278, 2016

80. Shapiro M, Raz E, Becske T, Nelson PK: Variable porosity of the pipeline embolization device in straight and curved vessels: a guide for optimal deployment strategy. AJNR Am J Neuroradiol 35:727-733, 2014

81. Strauss I, Maimon S: Silk flow diverter in the treatment of complex intracranial aneurysms: a single-center experience with 60 patients. Acta Neurochir (Wien) 158:247-254, 2016

82. Tähtinen OI, Vanninen RL, Manninen HI, Rautio R, Haapanen A, Niskakangas T, et al: Wide-necked intracranial aneurysms: treatment with stent-assisted coil embolization during acute ( $<72$ hours) subarachnoid hemorrhage-experience in 61 consecutive patients. Radiology 253:199-208, 2009

83. Tomasello A, Romero N, Aixut S, Miquel MA, Macho JM, Castaño C, et al: Endovascular treatment of intracraneal aneurysm with Pipeline embolization device: experience in four centres in Barcelona. Neurol Res 38:381-388, 2016

84. Turjman F, Acevedo G, Moll T, Duquesnel J, Eloy R, Sindou $\mathrm{M}$ : Treatment of experimental carotid aneurysms by endoprosthesis implantation: preliminary report. Neurol Res 15:181-184, 1993

85. Turk AS, Maia O, Ferreira CC, Freitas D, Mocco J, Hanel $\mathrm{R}$ : Periprocedural safety of aneurysm embolization with the
Medina Coil System: the early human experience. J Neurointerv Surg 8:168-172, 2016

86. van Rooij WJ, Peluso JP, Bechan RS, Sluzewski M: WEB treatment of ruptured intracranial aneurysms. AJNR Am J Neuroradiol 37:1679-1683, 2016

87. Wakhloo AK, Lylyk P, de Vries J, Taschner C, Lundquist J, Biondi A, et al: Surpass flow diverter in the treatment of intracranial aneurysms: a prospective multicenter study. AJNR Am J Neuroradiol 36:98-107, 2015

88. Wakhloo AK, Shellhammer F, de Vries J, Schumacher J: Coated and non-coated stents for vessel reconstruction and treatment of aneurysm and AV fistulas: an experimental study. Neuroradiology 34 Suppl:24, 1992 (Abstract)

89. Wang C, Tian Z, Liu J, Jing L, Paliwal N, Wang S, et al: Flow diverter effect of LVIS stent on cerebral aneurysm hemodynamics: a comparison with Enterprise stents and the Pipeline device. J Transl Med 14:199, 2016

90. Wang CB, Shi WW, Zhang GX, Lu HC, Ma J: Flow diverter treatment of posterior circulation aneurysms. A meta-analysis. Neuroradiology 58:391-400, 2016

91. Yavuz K, Geyik S, Saatci I, Cekirge HS: Endovascular treatment of middle cerebral artery aneurysms with flow modification with the use of the Pipeline embolization device. AJNR Am J Neuroradiol 35:529-535, 2014

92. Ye G, Zhang M, Deng L, Chen X, Wang Y: Meta-analysis of the efficiency and prognosis of intracranial aneurysm treated with flow diverter devices. J Mol Neurosci 59:158-167, 2016

93. Zanaty M, Chalouhi N, Starke RM, Jabbour P, Ryken KO, Bulsara KR, et al: Failure of the Pipeline embolization device in posterior communicating artery aneurysms associated with a fetal posterior cerebral artery. Case Rep Vasc Med 2016:4691275, 2016

94. Zhou G, Su M, Zhu YQ, Li MH: Efficacy of flow-diverting devices for cerebral aneurysms: a systematic review and meta-analysis. World Neurosurg 85:252-262, 2016

\section{Disclosures}

The authors report no conflict of interest concerning the materials or methods used in this study or the findings specified in this paper.

\section{Author Contributions}

Conception and design: all authors. Acquisition of data: all authors. Analysis and interpretation of data: all authors. Drafting the article: all authors. Critically revising the article: all authors. Reviewed submitted version of manuscript: all authors. Approved the final version of the manuscript on behalf of all authors: Rangel-Castilla.

\section{Correspondence}

Leonardo Rangel-Castilla, Department of Neurosurgery, Wayne State University School of Medicine, 4160 John R Rd., Ste. 925 , Detroit, MI 48201. email: leonardo.rangel-castilla@wayne.edu. 